\title{
Penerapan Perilaku Hidup Bersih dan Sehat (PHBS) Desa Wonosalam Demak
}

\author{
Muh. Isna Nurdin Wibisana \\ Universitas PGRI Semarang, Indonesia \\ muh.isnanw@gmail.com
}

Received: $23^{\text {rd }}$ March 2020 | Accepted: $29^{\text {th }}$ November 2020 | Published: $30^{\text {th }}$ January 2021

\begin{abstract}
\begin{tabular}{l}
\hline Key word: \\
\hline Sanitary \\
behavior; \\
level knowledge; \\
clean and health \\
\\
\hline
\end{tabular}
Abstract

Wonosalam Village is located on the banks of the Tuntang river which is the largest river in Demak. High rainfall often causes the overflow of the river to flood and cause seasonal diseases. This flood condition is exacerbated by the relatively low awareness of the community's clean life as seen from the large amount of waste that has not maintained well and the low quality of health of the residents of Wonosalam Village. The objectives of the activity are: 1) to find out the level of awareness of the community's PHBS; 2) provide practical understanding of clean and healthy life; 3) familiarize community control on PHBS, 4) improve the quality of a clean and healthy life. The methods used are surveys, lectures, discussions, and demonstrations. The results of this activity are 1) the level of understanding of residents and students as community partners regarding PHBS increases; 2) residents of Wonosalam village and students can perform several behaviors, such as washing hands with soap, exercising, brushing teeth, and carrying out proper waste disposal management; 3) residents and teachers can remind each other if there are residents or students who do not practice PHBS behavior; 4) the environment of Wonosalam villagebecomes more beautiful and clean and residents become more enthusiastic about living life.

Kata Kunci

Kebiasaan hidup bersih;

tingkat

pengetahuan;

kebersihan dan

kesehatan

\section{Abstrak}

Desa Wonosalam terletak di tepi sungai yang merupakan sungai terbesar di Demak. Curah hujan yang tinggi kerap mengakibatkan luapan sungai Tuntang menjadi banjir dan menyebabkan timbulnya penyakit musiman. Kondisi banjir ini diperparah dengan kesadaran hidup bersih masyarakat yang relatif masih rendah terlihat dari banyaknya sampah yang belum dibuah pada tempatnya serta kualitas Kesehatan warga Desa Wonosalam yang rendah pasca banjir. Tujuan kegiatan adalah: 1) mengetahui tingkat kesadaran PHBS warga; 2) memberikan pemahaman praktis menganai hidup bersih dan sehat; 3) membiasakan kontrol masyarakat tentang PHBS, 4) memperbaiki kualitas hidup bersih dan sehat masyarakat. Metode yang digunakan adalah survey, ceramah, diskusi, dan praktik serta demonntrasi. Hasil dari kegiatan ini adalah 1) tingkat pemahaman warga dan siswa sebagai mitra pengabdian mengenai PHBS meningkat; 2) warga desa Wonosalam dan siswa SD Wonosalam 1 dan SD Wonosalam 2 dapat melakukan beberapa perilaku yang menjadi indikator PHBS yaitu mencuci tangan dengan sabun, olah raga, menggosok gigi, dan melakukan manajemen pembuangan sampah dengan baik; 3) warga dan guru dapat saling mengingatkan jika terdapat warga atau siswa yang tidak
\end{abstract}

JDC Vol. 5 No. 1 (Januari - Juni 2020) 
menjalankan perilaku PHBS; 4) lingkungan desa Wonosalam, SD Wonosalam 1 dan SD Wonosalam 2 menjadi lebih asri dan bersih serta warga menjadi lebih bersemangat menjalani hidup.

\section{PENDAHULUAN}

Desa Wonosalam terletak di pinggiran pusat pemerintahan Kecamatan Wonosalam. Desa Wonosalam memiliki hampir sepertiga lahan untuk pertanian. Jumlah penduduk desa Wonosalam adalah 5.359 jiwa yang terdiri dari $74,4 \%$ penduduk dewasa dan $25,6 \%$ penduduk anak-anak (Statistik \& Demak, 2019). Desa ini berbatasan langsung dengan Kecamatan Guntur dan Kecamatan Karangtengah yang dipisahkan oleh Kali Tuntang. Kali Tuntang merupakan muara dan sungai terbesar di Kabupaten Demak. Kali Tuntang merupakan muara air dari Kabupaten Grobogan dan Kabupaten Demak yang selanjutnya berhilir di laut sebelah utara Pulau Jawa.

Sungai ini menjadi sumber air bagi lahan persawahan warga Desa Wonosalam. Debit air sungai cukup untuk digunakan warga mengairi persawahan. Kondisi berbeda terjadi pada musim hujan awal tahun 2020 yang lebih lebat daripada sebelum-sebelumnya. Hujan yang turun intensif membuat Kali Tuntang meluap sehingga mengakibatkan banjir. Selain itu, kondisi sungai yang dangkal akibat tidak ada persiapan mengantisipasi musim hujan berdampak pada volume air yang luar biasa.

Kondisi banjir dapat mengakibatkan beberapa masalah yang dihadapi oleh warga. Kerugian yang dialami bukan hanya berupa kerusakan rumah dan harta benda, tetapi juga wabah penyakit dan trauma selama dan pasca banjir (Kusuma et al., 2010). Anak-anak juga merupakan pihak yang rentan dengan penyakit pasca banjir (Taufiq, 2014). Kondisi Kesehatan pascabanjir dapat diperparah dengan rendahnya kesadaran warga berkaitan dengan lingkungan, hal ini terlihat pada sampah yang belum ditempatkan semestinya (Yuniarti et al., 2014). Sampah rumah tangga menjadi yang terbesar dalam produksi sampah warga desa Wonosalam.

Survey yang dilakukan oleh tim pengabdi menghasilkan data bahwa belum banyak warga yang memahami dengan baik mengenai Perilaku Hidup Bersih dan Sehat (PHBS). Program PHBS adalah upaya promosi kesehatan agar setiap orang dapat menciptakan kondisi yang kondusif bagi diri sendiri dan keluarga sehingga dapat tinggal di lingkungan yang bersih dan sehat (Rahman \& Patilaiya, 2018). Indikator PHBS sangat beragam menyesuaikan lokasinya, baik di sekolah, rumah, ataupun masyarakat.

Terdapat 10 indikator PHBS di rumah tangga, yaitu melaksanakan persalinan oleh tenaga kesehatan, memberikan ASI 
eksklusif, anak di bawah 5 tahun ditimbang setiap bulan, menggunakan air bersih, mencuci tangan dengan air bersih dan sabun, menggunakan jamban sehat, memberantas jentik nyamuk, makan sayur dan buah setiap hari, melakukan aktivitas fisik setiap hari dan tidak merokok di dalam rumah.

Tim pendamping pengabdian beserta mahasiswa KKN UPGRIS juga mendapatkan data bahwa terdapat lima sekolah dasar yang berada di desa Wonosalam. Hasil penelusuran awal menunjukkan bahwa masih terdapat siswa yang belum melaksanakan perilaku hidup bersih dan sehat dengan benar, tidak mandiri dalam menyelesaikan tugasnya seperti mencuci tangan sendiri, ke toilet sendiri dan sebagainya. Berkaitan dengan indikator PHBS di sekolah yang berhubungan erat dengan proses pembelajaran adalah mencuci tangan dengan air yang mengalir dan memakai sabun, menggunakan jamban yang bersih dan sehat, dan membuang sampah pada tempatnya (Lubis et al., 2019).

Berdasarkan survei yang telah dilakukan dan kondisi lapangan yang ada, tim pengabdi melakukan pendampingan pengabdian berupa pengenalan dan pembiasaaan PHBS untuk warga Desa Wonosalam Kecamatan Demak.

\section{METODE}

Kegiatan pengabdian yang dilakukan menggunakan metode sebagai berikut:

1. Survei awal mengenai kondisi lingkungan dan kesehatan masyarakat. Kegiatan ini dilakukan dengan pemetaan kondisi kesehatan desa Wonosalam dan cek kesehatan yang terdiri dari cek tekanan darah, cek berat badan, dan pemeriksaan umum yang dilakukan kepada kelompok warga;

2. Penyuluhan mengenai PHBS. Kegiatan ini menggunakan metode ceramah dan diskusi. Ceramah yang diberikan berisi materi mengenai gambaran umum PHBS, indikator-indikator PHBS, dan contoh-contoh perilaku yang mendukung PHBS. Diskusi dilaksanakan setelah kelompok warga mendapatkan materi dari tim pengabdi.

Praktik atau demonstrasi, tim pengabdi melakukan beberapa demonstrasi khususnya cara mencuci tangan dengan sabun, menggosok gigi dengan baik, dan olah tubuh atau senam.

\section{HASIL}

Kegiatan pengabdian yang dilakukan oleh tim pengabdi dan kelompok $\mathrm{KKN}$ Universitas PGRI Semarang bersama mitra mendapatkan hasil sebagai berikut:

1. Survey awal yang dilakukan menunjukkan hasil bahwa sebagian 
rumah tangga belum menjalankan PHBS dengan baik, demikian juga dengan beberapa siswa yang belum terbiasa mencuci tangan dengan sabun serta belum disediakannya tempat cuci tangan yang memadai di sekolah. Cek Kesehatan yang dilakukan oleh tim pengabdi diikuti oleh 28 warga desa Wonosalam. Hasil cek kesehatan menunjukkan rata-rata warga Desa Wonosalam yang berusia lebih dari 50 tahun mengalami beberapa gangguan Kesehatan seperti tensi tinggi, batuk, pilek, dan lesu. Kegiatan ini mendapat sambutan yang baik dari warga setempat karena selama ini pemeriksaan kesehatan dilakukan secara mandiri.

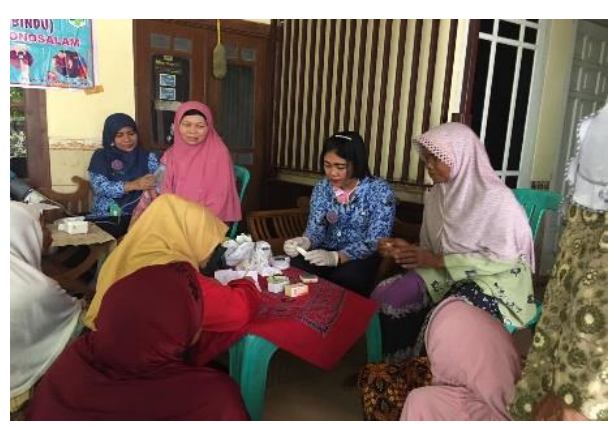

Gambar 1. Pemeriksanaan Kesehatan

2. Penyuluhan mengenai PHBS dilakukan kepada rumah tangga dengan memberikan paparan (ceramah) dan video infografis mengenai PHBS. Kegiatan penyuluhan di sekolah dilakukan dengan memberikan video contoh PHBS yaitu mencuci tangan, menggosok gigi, membuah sampah pada tempatnya.

3. Diskusi antara narasumber dengan mitra berlangsung dengan baik. Warga banyak menanyakan mengenai apa saja yang perlu disiapkan dalam menjalani PHBS dan bagaimana cara mengelola sampah yang baik.

4. Siswa sekolah dasar menyimak demonstrasi dari narasumber mengenai bagaimana cara menggosok gigi dan mencuci tangan dengan sabun yang baik dan benar;

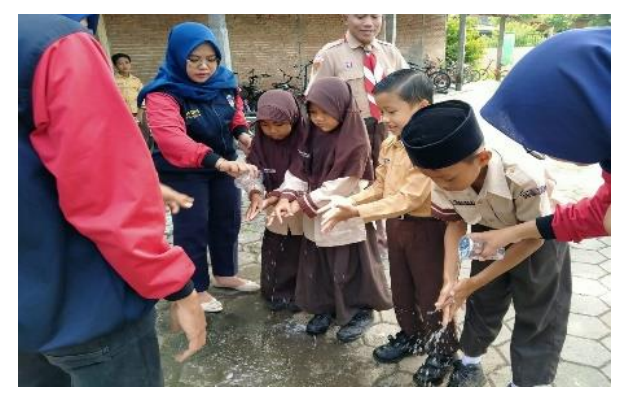

Gambar 2. Praktik mencuci tangan memakai sabun dan menggosok gigi.

5. Warga, siswa, dan tim pengabdi Bersama-sama membiasakan lagi olah raga atau senam aerobik agar tubuh diolah dengan baik dan meminimalisir kekakuan otot. Kegiatan ini dilakukan rutin dua kali dalam satu pekan secara bersama-sama dan setiap hari berupa peregangan otot mandiri; 


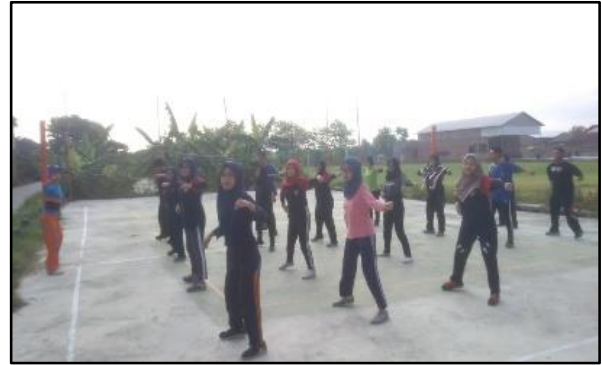

Gambar 3. Senam Aerobik sebagai olah tubuh

Mitra pengabdian memahami sistem kontrol lingkungan yang mengajarkan warga untuk saling mengingatkan.

\section{PEMBAHASAN}

Skrining awal PHBS dapat dilakukan melalui pemeriksaan Kesehatan tekanan darah, gula darah sewaktu menjadi salah satu cara untuk mengetahui tingkat kesehatan yang dapat digunakan sebagai jendela untuk melihat bagaimana kondisi kesehatan lingkungan (Imam Rofiki \& Siti Roziah Ria Famuji, 2020). Kegiatan PHBS di sekolah yang perlu untuk dilakukan secara terus menerus adalah mencuci tangan dengan sabun, membuang sampah pada tempatnya, dan membuang air di jamban (Simbolon \& Simorangkir, 2018).

Kegiatan penyuluhan pada pengabdian ini dilakukan dengan melibatkan warga dengan tujuan dapat meningkatkan efektivitas penyuluhan. Hal ini selaras dengan hasil penelitian yang menunjukkan bahwa partisipasi masyarakat menjadi penting dalam menentukan keberhasilkan sebuah program (Muslim, 2017).

Penggunaan media video dalam memberikan pemahaman kepada anak sekolah merupakan salah satu hal yang dapat meningkatkan efektivitas penyuluhan. Hal ini sebagaimana yang ditulis dalam sebuah penelitian yang menyebutkan video adalah gabungan antara audio visual yang mampu memberikan tingkat pemahaman yang lebih baik kepada siswa atau anak usia dibi dalam mempelajari atau memahami hal baru (Mulyadi et al., 2018).

\section{SIMPULAN}

Pelaksanaan Program Pengabdian Masyarakat ini berjalan dengan baik dan lancar, Desa Wonosalam Kecamatan Wonosalam Kabupaten Demak mampu menjadi desa mandiri dalam bidang kebersihan dan kesehatan. Hal ini didukung dengan potensi masyarakat setempat yang mampu melakukan cek kesehatan, perilaku hidup bersih dan sehat sejak dini dan aktivitas fisik yang menunjang kesehatan masyarakat. Kerjasama masyarakat di segala jenjang usia akan mampu menyadarkan peran masing-masing dalam bermasyarakat.

\section{SARAN}

Adapun saran pada program kemitraan masyarakat ini adalah: (1) Perangkat desa selalu mendampingi 
kegiatan yang ada sehingga akan terjalin kerjasama yang solid, (2) Kegiatan senam aerobik bisa untuk semua kalangan, jadi tidak hanya ibu-ibu saja, (3) Kegiatan perilaku hidup bersih selalu didampingi orang tua sehingga akan efektif keberlanjutannya, (4) Memberdayakan karang taruna sebagai tulang punggung kegiatan desa Wonosalam.

\section{UCAPAN TERIMA KASIH}

Ucapan terima kasih kami sampaikan pada:

1. Universitas PGRI Semarang yang telah memberikan kesempatan kepada tim untuk melakukan pengabdian.

2. Lembaga Penelitian dan Pengabdian Kepada Masyarakat Universitas PGRI Semarang yang telah menyetujui, memberikan bimbingan, pemberi dana serta arahan kepada tim.

3. Fakultas Pendidikan Ilmu Pengetahuan Sosial dan Keolahragaan yang memberikan dorongan serta kemudahan tim dalam melaksanakan program kemitraan masyarakat ini.

4. KKN Universitas PGRI Semarang yang membantu melakukan survei serta fasilitas saat melakukan kegiatan ini

\section{DAFTAR PUSTAKA}

Imam Rofiki, \& Siti Roziah Ria Famuji. (2020). Kegiatan Penyuluhan dan
Pemeriksaan Kesehatan untuk

Membiasakan PHBS bagi Warga Desa

Kemantren. Dinamisia : Jurnal

Pengabdian Kepada Masyarakat, 4(4), 628-634.

https://doi.org/10.31849/dinamisia.v4i 4.3992

Kusuma, M. S. B., Rahayu, H. P., Farid, M., Adityawan, M. B., Setiawati, T., \& Silasari, R. (2010). Studi Pengembangan Peta Indeks Resiko Banjir pada Kelurahan Bukit Duri Jakarta. Jurnal Teknik Sipil, 17(2), 123.

https://doi.org/10.5614/jts.2010.17.2.5

Lubis, Z. S., Lubis, N. L., \& Syahrial, E. (2019). Pengaruh penyuluhan dengan metode ceramah dan diskusi terhadap peningkatan pengetahuan dan sikap anak tentang PHBS. 3(2252), 58-66. http://www.tjyybjb.ac.cn/CN/article/d ownloadArticleFile.do?attachType $=P$ DF\&id=9987

Mulyadi, M. I., Warjiman., \& Chrisnawati. (2018). Efektivitas pendidikan kesehatan dengan media video terhadap tingkat pengetahuan perilaku hidup bersih dan sehat. Jurnal Keperawatan STIKES Suaka Insan, 3(2), 1-9.

Muslim, A. (2017). Analisis Kegagalan

Program Nasional Pemberdayaan

Masyarakat dalam Membangun 
Kemandirian Masyarakat Miskin

(Studi Kasus di Provinsi Daerah

Istimewa Yogyakarta, Jawa Tengah,

dan Jawa Timur). Jurnal Penyuluhan, 13(1), 79.

https://doi.org/10.25015/penyuluhan.v $13 i 1.14524$

Rahman, H., \& Patilaiya, H. La. (2018).

Pemberdayaan Masyarakat Melalui

Penyuluhan Perilaku Hidup Bersih

dan Sehat untuk Meningkatkan

Kualitas Kesehatan Masyarakat.

JPPM (Jurnal Pengabdian dan

Pemberdayaan Masyarakat), 2(2),

251.

https://doi.org/10.30595/jppm.v2i2.25

12

Simbolon, P., \& Simorangkir, L. (2018).

Penerapan UKS dengan PHBS di

Wilayah Kerja Puskesmas Pancur

Batu Kabupaten Deli Serdang.

JURNAL KESEHATAN

LINGKUNGAN INDONESIA, 17(1).

https://doi.org/10.14710/jkli.17.1.16-

25

Statistik, B. P., \& Demak, K. (2019).

Kecamatan Wonosalam Kecamatan

Wonosalam.

Taufiq, R. (2014). Gambaran Resiliensi

Anak Pasca Bencana Banjir Di Desa

Dayeuhkolot, Kabupaten Bandung,

Jawa Barat. Wacana Jurnal Psikologi,

6(11), 73-87.
Yuniarti, T., Nurhayati, I., Putri, A. P., Fadhilah, N., Kesehatan, F., \& Muhammadiyah, U. (2014). Pengaruh pengetahuan kesehatan lingkungan terhadap pembuangan sampah sembarangan. Jurnal Ilmiah Kesehatan, 78-82. 
p-ISSN : 2548-8783

e-ISSN : 2548-8791

8 | Journal of Dedicators Community Unisnu Jepara 